\title{
Halo nevus in the dermoscopy
}

\section{Kaoutar Achehboune, Safae zinoune, Hanane Baybay, Sara Elloudi, Fatima Zahra Mernissi}

\author{
Department of Dermatology-Venereology, Hospital University, Hassan II, Fez, Morocco
}

Corresponding author: Dr. Kaoutar Achehboune, E-mail: achehboune.kaoutar@gmail.com

Sir,

Halo nevus is a rare dermatological entity that corresponds to the appearance around a melanocytic nevus, most often acquired, of a whitish halo, thus achieving the Sutton phenomenon. In this article, we present a case of halo nevus on multiple nevi in a 9-year-old child, one of whom is congenital [1].

A 9-year-old child who presents since 8 months multiple whitish halos around the nevi of which one is congenital sitting at the level of his back and the scalp. He had no history of dermatological or dysimmunitary disease in the family. The examination revealed a well-defined hypochromic ring surrounding Sutton's nevi (Figs. 1 - 3). Our conduct was to monitor dermoscopically the evolution of these nevi.

The dermoscopic signs of a halo nevus are those of a benign melanocytic nevus, represented by regular and homogeneous globular and or reticular patterns, with a peripheral zone without a white structure arranged in a halo. Over time, the halo nevus presents considerable dermoscopic changes characterized by progressive involution with subsequent total regression of the central nevus. In addition, telangiectasia can be observed in the whitish halo or a normal appearance [2]. The peculiarity in our patient is the appearance of the halo on a congenital nevus which remains a rare entity [3]. It is important to note that the Sutton phenomenon on congenital nevus is frequently associated with the subsequent occurrence of a melanoma of "where the need for close dermoscopic follow-up [1,2] to search signs of malignancy: abrupt discontinuation of peripheral pigmentation, irregular radial striations, heterochromia, regression areas, mesh and/or irregular meshes.

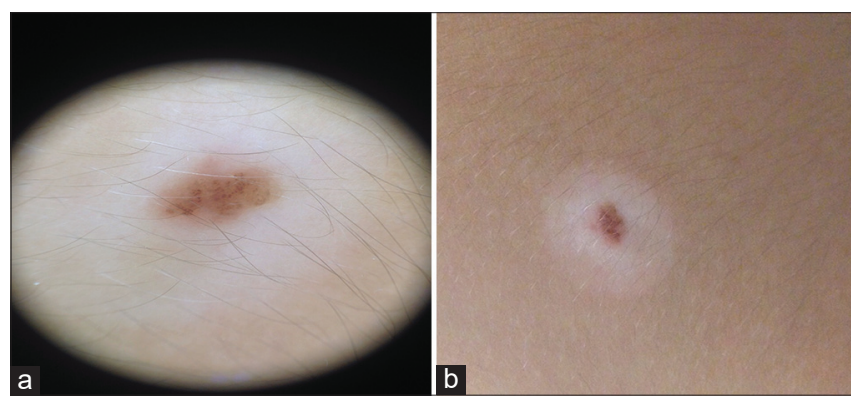

Figure 1: $(a$ and $b)$ Regular central globular pattern with zone of peripheral depigmentation in halo on a skin of phototype III.

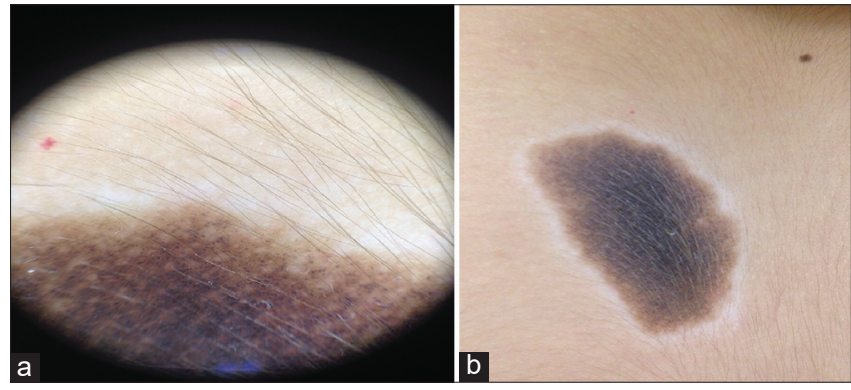

Figure 2: ( $a$ and b) Compound pattern made of regular and homogeneous reticular network with regular globules of similar size in the center and hypertrichosis, surrounded by a depigmentation zone on a skin of phototype III.

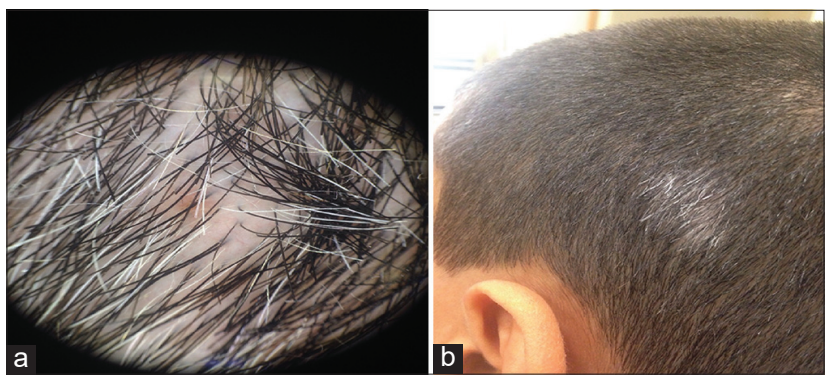

Figure 3: ( $a$ and $b)$ Scalp nevus having regressed in a quasi-totality revealing a light brown in the center of the pink zone with presence of telangiectasies in the whitish halo.

Dermoscopy allows more accurate diagnosis and management of melanocytic skin lesions. It is

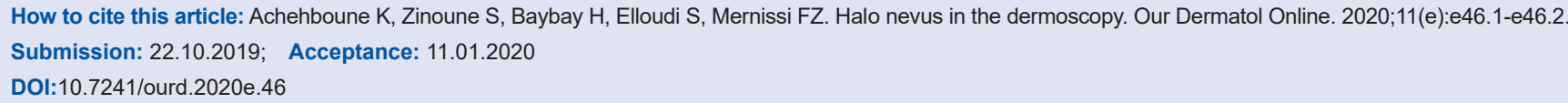


important to ensure that the central nevus has a typical melanocytic pattern to distinguish a halo nevus from melanoma regression areas and if a single lesion presents with suspicious signs a cutaneous biopsy is required.

\section{Consent}

The examination of the patient was conducted according to the Declaration of Helsinki principles.

The authors certify that they have obtained all appropriate patient consent forms. In the form the patient(s) has/have given his/her/their consent for his/ her/their images and other clinical information to be reported in the journal. The patients understand that their names and initials will not be published and due efforts will be made to conceal their identity, but anonymity cannot be guaranteed.

\section{REFERENCES}

1. Ben Said Z, Saidi W, Boussofara L, Abdennadher F, Aounallah A, Denguezli M, et al. Vitiligo et phénomène de Sutton chez un enfant porteur d'un naevus congénital, CHU Farhat Hached, Sousse, Tunisie 2012.

2. Szymszal J, Kaminska-Winciorek G. Dermoscopy of halo nevus in own observation. Postepy Dermatol Alergol. 2014;31:152-8.

3. Aouthmany M, Weinstein M, Zirwas MJ, Brodell RT. Natural history of halo nevi: a retrospective case series. J Am Acad Dermatol. 2012;67:582-6.

Copyright by Kaoutar Achehboune, et al. This is an open-access article distributed under the terms of the Creative Commons Attribution License, which permits unrestricted use, distribution, and reproduction in any medium, provided the original author and source are credited.

Source of Support: Nil, Conflict of Interest: None declared. 